\title{
Quadriláteros: uma Sequência Didática Construída com Recursos da Teoria das Situações Didáticas
}

\section{Quadrilaterals: a Didactic Sequence Constructed with Resources from the Theory of Didactic Situations}

\author{
Cileide Teixeira da Silva Pollia; Helenara R. Sampaio Figueiredo*bc; Marlene Alves Dias ${ }^{\text {bc }}$

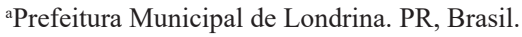 \\ bUnopar, Programa de Pós-Graduação Stricto Sensu em Metodologias para o Ensino de Linguagens e suas Tecnologias. PR, Brasil. \\ 'Universidade Anhanguera de São Paulo, Programa de Pós-Graduação Stricto Sensu em Educação Matemática. SP, Brasil. \\ *E-mail: helenara@kroton.com.br
}

\begin{abstract}
Resumo
Este artigo descreve parte de uma dissertação de mestrado já concluída que investigou possibilidades de um trabalho didático em Geometria. Teve como objetivo analisar as dificuldades de aprendizagem no conceito de quadriláteros, referentes às ideias de paralelismo e perpendicularismo. A partir deste propósito, apresenta os resultados da aplicação de uma sequência didática sobre polígonos, com ênfase na construção de situações adidáticas. A sequência foi elaborada com base em descritores da Prova Brasil e serviu como um dos instrumentos de coleta de dados da pesquisa. A pesquisa se enquadra no perfil qualitativo, do qual participaram dezessete alunos do $5^{\circ}$ ano do Ensino Fundamental da rede municipal de Londrina. Os resultados permitem observar a importância do protagonismo do professor e do aluno no processo de construção do conhecimento.
\end{abstract}

Palavras-chave: Quadriláteros. Sequência didática. Situações Didáticas e Adidáticas.

\begin{abstract}
This paper describes part of an already concluded master's thesis which investigated the possibility of a didactic work in Geometry. It aims to present the results of one of the moments of this work: the implementation of a didactic sequence on polygons, with emphasis on the construction of didactic and adidactic situations. The sequence was elaborated based on descriptors from Prova Brasil and served as one of the data collection instruments of the research. The participants, in addition to the teacher-researcher, are part of a class formed by seventeen students who attend the 5 th grade of elementary school, which is part of the municipal department of education in Londrina city, Parana state. Its results allow us to observe the importance of teacher and student protagonism on the process of knowledge construction.
\end{abstract}

Keywords: Polygons. Didactic Sequence. Didactic and Adidactic Situations.

\section{Introdução}

O ensino de Geometria, especificamente em relação à noção de quadriláteros, adquire grande relevância quando notamos como ela está presente no nosso dia a dia, nas formas da natureza, nos objetos que vemos e manuseamos, auxiliandonos a descrever o espaço em que vivemos, interagir com ele e compreendê-lo.

A proposição deste estudo amparou-se em autores como Lorenzato $(1995,2010,2015)$, que defende a presença da Geometria no ensino de Matemática, a partir do argumento de que este conhecimento deve ser construído desde a Educação Infantil, visto que auxilia na solução dos problemas do cotidiano, os quais, muitas vezes, são geometrizados. Também se embasou na concepção trazida por Passos $(2000,2010)$ e Pavanello (1993), de que a instrução dos saberes geométricos deve ser iniciada nos primeiros anos do Ensino Fundamental.

A par da importância da Geometria, ratificada pelos autores que embasam este artigo, é importante ponderar acerca das dificuldades dos alunos na compreensão dos conceitos e propriedades associados aos quadriláteros, divulgadas por pesquisas como as de Proença e Pirola (2009), nas quais os autores enfatizam a necessidade de buscar formas eficientes de trabalhar os conceitos geométricos nas escolas, ressaltando a importância desses estarem alicerçados em recursos como informática, materiais manipulativos, entre outros, que podem auxiliar no desenvolvimento de habilidades de visualização, desenho, argumentação lógica e de aplicação em solução de problemas.

$\mathrm{Na}$ pesquisa de mestrado que deu origem ao presente artigo, optamos por trabalhar com uma sequência didática como processo interativo, com respaldo na proposta de Sampaio (2008), tendo como intuito contemplar as respostas dos alunos e as condições às quais estão submetidas. Nessa perspectiva, tornou-se possível identificar a necessidade de criação de situações adidáticas que complementassem as atividades inicialmente propostas, com a finalidade de propiciar o desenvolvimento do pensamento geométrico nos estudantes.

Isso nos conduziu a buscar nos aportes teóricos de Brousseau (2008) a compreensão de que as situações adidáticas, correspondem à parte da situação didática na qual a intenção de ensinar não é explícita para o aluno. Nessa 
perspectiva, o sujeito apropria-se da situação, isto é, toma a situação para si, cabendo ao aluno tomar as decisões, engajar estratégias e avaliar a eficácia das mesmas.

Apresentamos um recorte da dissertação, ou seja, optamos pelo quinto momento de aplicação da sequência didática, dentre os sete momentos considerados na pesquisa. A escolha se deve ao fato que este momento envolveu a noção de quadriláteros, considerada ampla no âmbito da Geometria Plana, que requer do aluno capacidade de abstração, vinculada à visualização e à representação.

\section{Sequência Didática e a Criação de Situações Adidáticas}

As sequências didáticas, conforme postula Zabala (1998), representam uma maneira de encadear e articular as diferentes atividades ao longo de uma unidade didática, a fim de que os resultados alcançados e as possíveis intervenções na execução dessas atividades possam ser analisados. Esse tipo de intervenção possibilita ao aluno a construção de seus próprios conhecimentos, ao suscitar indagações, refutações e comparações, integrando as informações obtidas e descobertas.

Zabala (1998) destaca ainda a manutenção de interações entre professor e alunos, que são instigados a usar sua intuição, fazer conjecturas e buscar sua elaboração mental para a construção dos conhecimentos. Na perspectiva apontada por este autor, embora existam diferentes tipos de sequência didática, cada qual possui possibilidades e carências. Por esse motivo, é importante que busquemos reconhecer a que melhor se adapta às necessidades educacionais de cada aluno, em determinados contextos e de acordo com a dimensão em que se deseja trabalhar.

Assim, na escolha do quadro teórico apresentado neste artigo, elegemos alguns elementos da Teoria das Situações Didáticas (TSD) de Brousseau (2008), sobretudo quanto à importância da organização do meio, com o objetivo de provocar mudanças, visando desestabilizar o sistema didático habitual e propiciar o surgimento de conflitos, contradições e possibilidades de aprendizagem de novos conhecimentos. Nessas condições, o teórico adverte que, no processo de aprendizagem, deve haver condições para que o aluno realize, ele mesmo, suas aproximações sobre determinados procedimentos e raciocínios que não são e nem deveriam ser explicitados pelo professor.

A partir de uma situação adidática, retomamos a concepção de Nagata (2016), que afirma que as noções de Geometria são instrumentalizadas, de maneira intuitiva, nas atividades cotidianas, tais como a leitura de imagens e mapas, estacionar um carro ou promover tomadas de decisão sobre como mobiliar a casa. A tarefa básica das aulas de Geometria consiste em formar tais noções, ao lado das demais áreas da Matemática iniciadas na alfabetização.

Nas situações adidáticas o professor deixa de intervir como possuidor de conhecimentos, o aluno, mesmo sabendo que o problema foi escolhido pelo professor, deve saber que o novo conhecimento construído é inteiramente justificado pela lógica interna da situação.

Observamos que, nas situações adidáticas, as interações dos alunos com o meio são consideradas suficientemente "perspicazes e adequadas" para que os alunos possam construir conhecimentos, formular estratégias de ação, validar as ações, validar os saberes utilizando as retroações com esses meios, sem que suas atividades sejam orientadas pela necessidade de satisfazer as supostas intenções do professor.

Para o desenvolvimento da pesquisa utilizamos diferentes abordagens o que nos conduziu a considerar a Teoria das Situações Didáticas (Brousseau, 2011). Em relação ao quinto momento de aplicação da sequência didática, ou seja, a parte da pesquisa contemplada neste artigo, foi considerado como referencial teórico da pesquisa a TSD, surgida em 1970 como simples método de descrição e interrogação matemática dos dispositivos psicológicos e didáticos, se desenvolvendo constantemente sob os efeitos de novas questões e observações empíricas que ela tem vocação de produzir e relacionar.

Desse modo, a TSD modela as condições sobre as quais os seres humanos produzem, comunicam e aprendem conhecimentos que reconhecemos como matemáticos. Essas condições são modeladas por sistemas denominados situações, que conduzem os agentes em interação com ela a manifestar esse conhecimento.

Brousseau (2011) ressalta ainda que as situações se distinguem pela sua estrutura, suas regras, seu funcionamento, as formas de produzir conhecimento, etc. Isso o conduz a reagrupá-las em dois grandes tipos: as "situações matemáticas" para as quais nenhuma intervenção didática é visada e as "situações didáticas" que compreendem as situações matemáticas, incorporadas em um sistema de condições que conduzem o sujeito à adoção direta de determinados comportamentos, apenas pela intervenção do professor, nas quais o aluno percebe ou não a necessidade da Matemática. Além disso, as situações matemáticas destinam-se a representar as condições mínimas necessárias para explicar ou justificar a implementação de um enunciado matemático por um agente ou grupo de agentes, sem intervenção didática exterior. Como exemplo, o autor cita as formas mais simples de situações matemáticas utilizadas no ensino há vários séculos, ou seja, os exercícios e os problemas. Para o autor, um contrato didático corresponde a um conjunto de comportamentos específicos do professor que são esperados pelos alunos, e um conjunto de comportamentos do aluno que são esperados pelo professor mediados pelo saber (Brousseau, 1996, p.38).

A TSD ilustra as diversas maneiras que a Matemática intervém em didática, como objeto de estudo, ou seja, a matemática didática, organizada para o ensino, como fonte de engenharias, que permite produzir novas organizações, problemas e situações matemáticas como meios de modelagem didática da matemática, como forma de análise estatística, epistemológica, semiológica entre outras. 
Consideramos neste extrato de pesquisa a TSD enquanto matemática didática, isto é, como fonte de modelagem de engenharias que permite a produção de novas organizações e situações matemáticas. Sob este ponto de vista, nos parece importante iniciar destacando os objetos estudados na TSD, a saber:

a) O saber matemático e o saber escolar, ressaltando que o saber escolar, obtido a partir da transposição didática do saber sábio, será uma implementação fictícia da gênese dos saberes, pois para se tornar saber a ensinar, será isolado em noções, propriedades e problemas.

b) O papel do professor, que não se reduz somente à exposição de saberes e problemas, mas de construtor e desenvolvedor de situações que forcem o aluno a colocar questões e procurar respondê-las, situações estas que visam à construção dos saberes escolares, isto é, o professor recontextualiza o saber. Para tanto, o aluno precisa reconstruir o conhecimento que permite resolver o problema, o que conduz a repersonalização do saber matemático. Desse modo, os conhecimentos produzidos na classe serão novamente descontextualizados e despersonalizados para constituírem o saber a reter. Esses saberes assumirão seu lugar no conjunto de saberes anteriores e conduzirão a reconsiderá-los e remanejá-los.

c) O trabalho dos alunos, que não devem aprender somente as definições, os teoremas e as técnicas e reter os problemas e os métodos utilizados para resolvê-los. Eles devem também se apoderar de um problema complexo novo, colocar questões, discutir sobre a qualidade das questões, produzir respostas (encaminhamentos, formalizações, provas) e discutir a pertinência das mesmas.

Para a construção e implementação da TSD, Brousseau (1998) considera inicialmente que fica a cargo do professor procurar uma situação didática, considerada como aquela que permite caracterizar um conjunto de problemas, que correspondem ao conhecimento. Além disso, é preciso que o aluno seja capaz de resolvê-lo. Essa situação é denominada situação fundamental.

A situação fundamental deve ser elaborada pelo professor, que irá propor a seus alunos, cabendo a estes apropriar-se da mesma e resolvê-la de modo a construir o conhecimento visado, que irá adquirir o status de saber. Ainda segundo Brousseau (1998), a pesquisa de situações fundamentais necessita uma análise epistemológica dos saberes, cujas articulações complexas tornam necessária a reflexão sobre a organização do ensino.

A implementação da TSD nos processos de aprendizagem se decompõe em quatro fases:

a) Fase de ação: corresponde à proposta de uma situação adidática relativa a um determinado conhecimento, isto é, trata-se de propor uma situação em que o conhecimento do sujeito se manifesta apenas por decisões, por ações regulares e eficazes sobre o meio, em que não é importante para a evolução das interações com este mesmo meio, que aquele que realiza a ação possa ou não identificar, explicitar ou explicar o conhecimento necessário.

b) Fase de formulação de um conhecimento relativo à situação adidática corresponde ao momento que coloca em relação pelo menos dois atores com o meio, pois o sucesso de ambos exige que de uma forma qualquer um deles formule o conhecimento em questão, de forma que o outro tenha necessidade de converter essas formulações em uma decisão eficaz sobre o mesmo meio. Sendo assim, a formulação consiste, para esse par de atores, em utilizar um repertório conhecido para formular uma mensagem original, sendo que a situação pode ainda modificar esse repertório. Ainda segundo Brousseau, podemos deduzir teoricamente e verificar experimentalmente que uma formulação "espontânea" de conhecimento exige que esse conhecimento exista previamente como modelo implícito de ação para os dois atores.

Modelo implícito de ação, faz parte da fase de formulação e é inicialmente uma descrição sistemática tão simples quanto possível dos comportamentos de um ator em uma situação. Esta descrição é denominada estratégia (válida para todos os casos) ou tática (válida para determinados casos). Esse modelo pode ser utilizado para tentar prever os comportamentos efetivos de um sujeito, mas ele é construído pelo observador por meio de critérios objetivos, tendo o sujeito que está sendo observado consciência ou não do que ele faz e do que é ou não capaz de explicitar. Desse modo, em TSD o modelo implícito de ação é uma representação simplificada da maneira que um conhecimento, sob uma forma particular, pode determinar os comportamentos de um ator em uma determinada situação. Essa representação do funcionamento dos conhecimentos em decisões, segundo sua validade e sua utilidade em circunstâncias precisas, é o instrumento fundamental da TDS enquanto epistemologia experimental, trata-se de um estudo crítico do conhecimento da matemática em jogo na situação.

c) Fase de validação social e cultural de uma situação adidática: corresponde ao momento em que a solução exige que os atores estabeleçam juntos a validade do conhecimento característico da situação, sua realização efetiva depende da capacidade dos protagonistas de estabelecer conjuntamente essa validade. Essa fase se apoia sobre o reconhecimento por todos de uma conformidade com a norma, de uma construção formal em certo repertório de regras ou teoremas conhecidos, e/ou da adequação consciente para resolvê-la. A fase de validação implica que os protagonistas confrontem suas opiniões sobre a evolução do meio e entrem em comum acordo, segundo as regras do debate cientifico.

d) Fase de institucionalização de um conhecimento: corresponde à situação que passa de seu papel de meio de resolução de uma situação de ação, de formulação ou de prova e assume um novo papel, o de referências para futuras 
utilizações, pessoais ou coletivas. Exemplo: problemas que após sua solução podem ser declarados típicos para se tornar um método ou teorema, que após demonstrados poderão ser usados sem refazer a demonstração.

É a institucionalização que permite ao professor e ao aluno reconhecer e legitimar o objeto de ensino, mesmo se eles o veem de formas diferentes.

\section{Material e Métodos}

O presente artigo é um recorte de uma dissertação de mestrado, na qual foi aplicada uma sequência didática a alunos do quinto ano do Ensino Fundamental I, de uma escola da rede municipal de ensino de Londrina, Paraná. A aplicação da sequência didática foi realizada no segundo semestre letivo do ano de 2017. A turma selecionada era composta por dezessete alunos, sendo sete do sexo feminino e dez do sexo masculino, com idades compreendidas entre nove e onze anos. Previu-se trinta aulas, distribuídas em 2 horas diárias, durante três dias por semana, totalizando um período aproximado de 45 dias.

O quinto momento, com duração de oito aulas, teve como objetivo identificar o paralelismo e o perpendicularismo nos quadriláteros; classificar os quadriláteros em paralelogramo e não paralelogramo, em paralelogramo retângulo e não retângulo; e classificar trapézio em retângulo e não retângulo. As atividades envolveram a identificação de figuras geométricas em obras de arte; exploração de uma das telas de Mondrian e identificação de retas paralelas e perpendiculares; classificação dos quadriláteros; exploração do paralelogramo no GeoGebra. Houve ainda a formulação de uma situação adidática, buscando aprofundar as noções de paralelismo e perpendicularismo, quando foi proposta uma atividade de localização no mapa do entorno da escola, após a observação em campo.

Para a coleta de dados, foram feitos por meio de registros de imagens, vídeos e recolhidos protocolos escritos dos alunos. Nas aulas em que foram realizadas atividades com o GeoGebra, foram feitas gravações em áudio.

Os procedimentos metodológicos que sustentaram a proposição da sequência didática, base de nossa pesquisa, apoiam-se em elementos da Engenharia Didática. Tratase de uma metodologia de pesquisa estruturada em quatro fases: análises preliminares, concepção e análise a priori, experimentação, análise a posteriori e validação.

A opção por utilizar alguns elementos da metodologia da Engenharia Didática vincula-se ao interesse pela ampliação dos nossos conhecimentos, pois buscamos inovar, propondo uma ação pedagógica que ao estabelecer uma relação entre um projeto de estudo de determinado saber matemático e o projeto construído por um engenheiro aponta de forma mais clara os elementos importantes a serem considerados na elaboração do projeto, em seu desenvolvimento, as possibilidades de retroação e a análise do resultado final por meio da comparação entre o que se previu e o que se realizou.

$\mathrm{Na}$ análise a priori, segunda fase da Engenharia Didática, usamos um instrumento de avaliação para a diagnose inicial, composto por onze questões, sendo duas abertas e nove fechadas. Foi elaborada uma avaliação diagnóstica com base em questões da Prova Brasil e outras fontes, no intuito de identificar os conhecimentos que os alunos já possuíam em relação aos polígonos. O objetivo desse instrumento foi fazer um levantamento dos conhecimentos prévios dos alunos sobre o conteúdo de polígonos, contemplado na proposta pedagógica para o quarto e o quinto ano.

A observação das dificuldades dos alunos quanto ao conteúdo dos polígonos contribuiu para a elaboração de nossa sequência didática, seus objetivos, seus aspectos matemáticos e didáticos, levando em consideração os aspectos levantados nas análises preliminares. Ainda com base nos estudos realizados, formularam-se as seguintes questões: 1. Uma sequência didática utilizando materiais manipuláveis pode contribuir na construção dos conceitos de polígonos? 2. Os alunos relacionam os conhecimentos de Geometria construídos ao utilizar o GeoGebra com os conceitos que envolvem o ensino de polígonos?

Diante dessas questões e dos demais estudos, levantouse também a hipótese de que o ensino de Geometria pode ser otimizado pela utilização de materiais manipuláveis e do software de Geometria dinâmica. Na análise a posteriori, quarta fase da Engenharia Didática, além de comparar os resultados obtidos na realização da sequência didática, foi empregado o mesmo instrumento de avaliação, com o objetivo de avaliar os resultados alcançados após a aplicação da sequência didática.

Para a validação, analisamos os resultados apresentados na sequência didática e comparamos as diagnoses inicial e final, sobretudo nas questões que diziam respeito aos conceitos de polígonos e às dificuldades elencadas como hipóteses na fase da análise a priori, na qual fizemos previsões quanto às possíveis dificuldades de aprendizagem dos alunos e ao desempenho deles nas atividades, construindo situações adidáticas que poderiam contribuir para o desenvolvimento do pensamento geométrico.

\section{Resultados e Discussão}

Antes de iniciar a apresentação dos resultados e discussão do quinto momento, nos parece importante explicitar quais os conhecimentos relacionados ao conceito de polígono que foram desenvolvidos por meio de sequências didáticas específicas nos momentos anteriores. No primeiro momento o objetivo era levar os alunos a descobrir, por si só, as principais propriedades que definem os polígonos por meio da situação adidática. No segundo momento, deveriam classificar os polígonos pela quantidade de lados que possui.

No terceiro momento, identificar ângulo reto, agudo e obtuso com uso de um instrumento de medida e no quarto momento, identificar e reconhecer os ângulos internos de um triângulo qualquer e verificar que os triângulos podem ser classificados tanto pelos lados quanto pelos ângulos. 
Em função dos quatro momentos anteriores, consideramos que os alunos, mesmo aqueles que ainda não tinham elementos para identificar, explicar e explicitar o conhecimento necessário, já eram capazes de interagir com o meio e formular conjecturas a partir das situações propostas. $\mathrm{Na}$ avaliação diagnóstica constante na Prova Brasil, os alunos deveriam identificar, dentre os polígonos apresentados, aquele que possuísse dois lados paralelos e dois lados não paralelos. Apenas 2 alunos acertaram, sinalizando $12,5 \%$ do total que atingiu o objetivo, e 14 foi o número de respostas incorretas, o que aponta para $87,5 \%$ da amostra. O paralelismo também é um conteúdo do quarto ano, mas pode-se pressupor que não tenha sido trabalhado de forma contextualizada para garantir o domínio efetivo do conceito.

A experimentação do quinto momento se deu a partir do planejamento a seguir: $1^{\text {a }}$ Atividade - identificação de figuras geométricas em obras de arte; $2^{\text {a }}$ Atividade - exploração de uma das telas de Mondrian e identificação de retas paralelas e perpendiculares; $3^{\mathrm{a}}$ Atividade - classificação dos quadriláteros; $4^{\mathrm{a}}$ Atividade - exploração do paralelogramo no GeoGebra; Atividade extra: Paralelismo, perpendicularismo e localização no mapa do entorno da escola.

As atividades foram desenvolvidas a fim de que os alunos pudessem identificar o paralelismo e o perpendicularismo nos quadriláteros; classificar os quadriláteros em paralelogramo e não paralelogramo, em paralelogramo retângulo e não retângulo e classificar trapézio em retângulo e não retângulo.

No quinto momento da sequência didática que constituiu a parte prática de nossa dissertação, foram trabalhados os quadriláteros. A primeira atividade consistiu em mostrar aos alunos algumas telas de artistas, como Tarsila do Amaral, Hélio Oiticica e Piet Mondrian, a fim de explorar as figuras geométricas utilizadas na composição das suas obras. Foram questionados sobre as semelhanças entre as obras e as cores predominantes e receberam informações sobre a vida e obra dos artistas. Não houve dificuldades por parte dos alunos em reconhecer os quadriláteros, pois em momentos anteriores da sequência didática já haviam trabalhado com este conteúdo.

Foi dada ênfase às telas de Mondrian pela presença de retas paralelas e perpendiculares. Estimulamos os alunos a procurar exemplos de paralelismo e perpendicularismo no ambiente da sala de aula. Na sequência, durante a segunda atividade, foi entregue a reprodução de uma das obras (New York City, 1942), para que os alunos explorassem, usando a régua e o ângulo de 90 graus construído em momento anterior da sequência didática. Os alunos deveriam utilizar seus discos com ângulos de 90 graus para medir o encontro dessas duas retas, sendo então informados que, quando duas retas se cruzam, formando ângulos de 90 graus, recebem o nome especial de retas perpendiculares entre si.

Embora os alunos tivessem se empenhado na realização das atividades propostas, observamos que ainda existiam dúvidas na formulação de conceitos relacionados aos ângulos, ou seja, eles eram capazes de identificá-los, mas não de explicar, permanecendo assim na fase de ação.

Observamos que os alunos utilizaram uma régua e mediram, na tela apresentada, a distância entre duas retas em dois pontos diferentes, com o objetivo de identificar a ocorrência ou não de paralelismo entre elas, ou seja, uma tentativa de mostrar que as retas mantinham a mesma distância, o que foi discutido na sequência para chegar à conclusão que retas paralelas nunca se cruzam. Do mesmo modo, para as retas cujo cruzamento era possível identificar um ângulo de 90 graus, vários alunos concluíram que eram perpendiculares, mas todas essas observações foram realizadas por meio da ação que conduziu à identificação, explicitação e justificativa da propriedade pelo grupo de alunos. Na terceira atividade do quinto momento da sequência, os alunos, individualmente, receberam duas folhas sulfites contendo vários tipos de quadriláteros, sendo-lhes solicitado que marcassem com cores diferentes cada par de retas paralelas encontradas nos quadriláteros dados.

Figura 1 - Atividades com quadriláteros

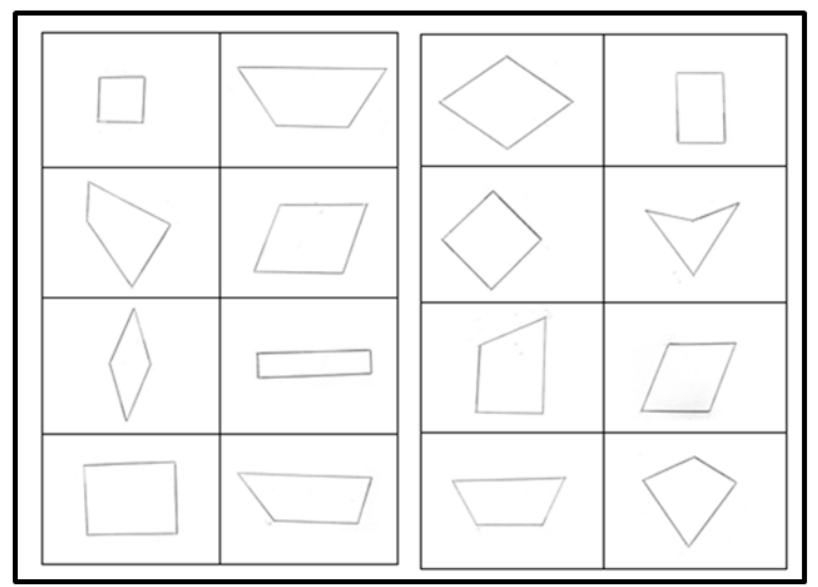

Fonte: Dados da pesquisa.

Em função das dificuldades ainda apresentadas por vários alunos, que não conseguiam encontrar um modo para identificar retas paralelas, depois de algum tempo, a professora/ pesquisadora solicitou que eles fizessem o prolongamento dos lados das figuras com a régua, para verificar se eram paralelas. Para nossa surpresa, percebemos que alguns alunos tinham dificuldades em manusear a régua, o que nos conduziu a trabalhar, mais particularmente, o losango e o trapézio, pois para figuras mais conhecidas, como o quadrado e o retângulo, a atividade seguiu conforme o previsto, mas ao se depararem com o trapézio, figura ainda desconhecida por eles, foi necessário considerar um tempo maior para a fase de ação e formulação.

Para figuras como o losango e o trapézio, constatamos que os alunos tiveram dificuldades em traçar as retas e como já haviam utilizado o geoplano, sentiram necessidade de manipular as figuras neste material para formular suas conjecturas.

Todavia, apesar de manipularem as figuras por meio do 
instrumento por eles conhecidos, ainda não eram capazes de reconhecer, mesmo na ação, paralelismo para as figuras menos conhecidas, como o paralelogramo, trapézio escaleno e isósceles, losango e quadriláteros. Para essas figuras, a dificuldade se apresentou também na construção usando o geoplano e, em virtude disso, cometeram equívocos na identificação de retas paralelas. Observamos que a representação das figuras geométricas não é auto-evidente, bastando apenas representá-las e identificá-las e classificá-las, sendo necessário que o aluno compreenda suas propriedades para ser capaz de diferenciá-las. Ressaltamos que a situação proposta exigiu um tempo maior do que o previsto, pois não havíamos considerado a necessidade de reintroduzir o geoplano, nem tampouco a ocorrência de dificuldades em visualizar retas paralelas.

Considerando as dificuldades ainda persistentes, solicitamos, então, que recortassem as figuras e formassem conjuntos diferentes, usando critérios próprios a partir dos conceitos espontâneos de retas paralelas, devendo elaborar cartazes. Era esperado dos alunos que separassem os quadriláteros em três grupos com dois pares de paralelas, um par de paralelas e sem retas paralelas, e todos os grupos atingissem o objetivo previsto. $\mathrm{Na}$ sequência, elaboraram cartazes com as figuras que haviam sido trabalhadas.

Apesar dos alunos evoluírem durante o desenvolvimento da situação, é importante enfatizar que muitos elementos previstos na análise a priori apresentaram dificuldades não previstas, pois já no quinto momento existiam alunos para os quais precisamos dar uma atenção especial, auxiliando-os na construção de algumas das figuras. Apesar da professora/ pesquisadora ser mediadora da situação, devendo participar o menos possível, foi necessário intervir, como nesse momento, para que os alunos continuassem motivados e pudessem prosseguir procurando resolver a situação proposta, utilizando os conhecimentos que dispunham e os novos conhecimentos.

Após a discussão sobre retas paralelas e perpendiculares e esclarecidas as dúvidas em relação à terceira atividade, passamos à releitura de uma obra de Piet Mondrian, ou seja, utilizando cartolina, tiras de papel, embalagens em forma de cubo e/ou de paralelepípedo e tinta para pintura das caixas de tamanhos variados, os alunos construíram suas próprias obras, inspirados no modelo do artista. A atividade transcorreu como previsto, uma vez que os alunos mostraram ser capazes de interagir com o meio identificando, explicitando e explicando como utilizavam os conhecimentos sobre paralelismo, perpendicularismo e as formas tridimensionais. Além disso, essa atividade permitiu desenvolver a criatividade e a produção estética dos alunos.

Para executar essa atividade, foi solicitado que os alunos trouxessem diferentes embalagens de papelão, sendo então questionados sobre as pontas, se elas rolavam com facilidade e se tinham o mesmo formato. A turma percebeu que a maioria das embalagens trazidas tinha pontas, apenas uma era diferente (a de Toblerone $\left.{ }^{\circledR}\right)$, então explicamos o porquê, dizendo que o formato de base triangular é pouco utilizado, porque os demais formatos de embalagem, com base quadrada e retangular, facilitam o empilhamento em supermercados, farmácias etc. Assim, os alunos observaram que a maioria das embalagens tinha formatos parecidos.

Sugerimos que contassem os lados de suas embalagens e observaram também que a maioria tinha a mesma quantidade de lados, a diferença da embalagem de Toblerone ${ }^{\circledR}$. A turma deveria apontar quais figuras geométricas planas conseguiam visualizar nos lados de suas embalagens. Os alunos rapidamente identificaram o formato retangular, seguido pelo quadrado e pelo triângulo, no caso do Toblerone ${ }^{\circledR}$. Explicamos, então, que figuras com aquelas características recebiam nomes especiais em Geometria. Após este momento, os alunos contornaram suas caixas para observar os formatos das faces.

Em seguida, escolheram algumas embalagens para pintar, pois eles iriam compor, na aula seguinte, uma tela parecida com a de Mondrian. No dia seguinte, cada aluno criou sua tela, o que correspondeu à nossa proposta de trabalhar a bidimensionalidade e a tridimensionalidade por meio da representação de polígonos e poliedros. Apesar de ser proposto um trabalho individual, os alunos realizaram a tarefa em grupo, todos se ajudaram. Era previsto que os alunos usassem o instrumento de medir ângulos e a régua, mas rapidamente muitos abandonaram a ideia e acabaram usando as caixas como medidas.

Observamos que um dos alunos formulou o processo de medida de ângulos por eles utilizado e outros validaram sua resposta, o que não havia sido previsto na análise a priori, pois havíamos pensado em utilizar materiais existentes no contexto escolar e os alunos, mesmo não tendo consciência, usaram um método prático que, em geral, os pedreiros empregam. Isso nos conduz a ressaltar a importância de repensar nossa prática e dar mais voz aos alunos, procurando ouvi-los e analisar suas respostas, pois nelas podem aparecer formas de uso da matemática por nós desconhecidas, ou seja, é preciso que o aluno mostre como está construindo seu conhecimento e a partir dele podemos ampliar e mostrar a existência de novas formas de tratar esse mesmo conhecimento, levando o mesmo a compreender a importância da matemática no seu cotidiano.

Para melhor compreender se os alunos eram capazes de validar os conhecimentos por eles adquiridos até o quinto momento, foi proposta uma atividade extra, incluindo os conceitos de paralelismo e perpendicularismo em uma representação do mapa do entorno da escola, na qual foi aplicada a sequência didática.

Solicitamos que os alunos pintassem o quarteirão em que está localizada a escola e não houve dificuldades. Depois, deveriam escrever o nome de uma rua paralela à Zacarias de Góes e o nome de uma rua perpendicular à Rua Um. Em relação ao paralelismo, os doze alunos que realizaram a atividade deram respostas adequadas, ou seja, eles eram capazes de identificar o paralelismo mesmo sem a utilização 
de materiais específicos. Em relação ao perpendicularismo, onze alunos responderam à questão conforme previsto e um afirmou que existia perpendicularismo no encontro da Rua Visconde de Guarapuava com a Barão de Jaraguá, sem prestar atenção para o fato de que esse cruzamento apresenta uma inclinação, quase imperceptível. Inferimos que o aluno não localizou a Rua Um na figura. Logo, os alunos parecem ter internalizado as noções de paralelismo e perpendicularismo, não necessitando de materiais concreto para identificá-las.

Observamos que mesmo a situação tendo sido construída para ser trabalhada pelos alunos com pouca interferência do professor, é importante ressaltar que ainda foram necessárias algumas intervenções específicas para que os alunos pudessem avançar no seu desenvolvimento. Apesar disso, as interações com o meio realizadas pelos alunos mostram que eles podem dar muitas contribuições utilizando ferramentas não escolares que fazem parte da matemática do cotidiano por eles vivenciada.

Ao retomarmos a discussão em torno desta atividade, quando exploramos brevemente o mapa do entorno da escola, ponderamos que este trabalho poderia ser ampliado com a inserção de atividades com o Google Maps, observando retas e quadriláteros e considerando o formato das quadras que compõem o espaço urbano. Essa, porém, é uma atividade que requer não apenas tablets e computador, mas o acesso à Internet, condições nem sempre presentes nas instituições escolares. Uma representação de um mapa em tamanho ampliado poderia ser uma alternativa para suprir a falta dos recursos tecnológicos.

Tendo sido expostos os resultados da aplicação das atividades do quinto momento, devemos reforçar que a contribuição observada esteve na oportunidade dada aos alunos de se manifestarem, tendo a professora mediado a situação incluindo novos elementos ao meio quando verificou que os alunos tinham dificuldades de continuar o desenvolvimento do trabalho proposto.

$\mathrm{Na}$ análise a posteriori, foram aplicadas as mesmas questões da diagnóstica com o intuito de comparar os resultados após a aplicação da sequência didática e encontrar subsídios para a validação - última etapa da Engenharia Didática -, na qual são confrontados os dados obtidos na análise a priori e a posteriori.

Na questão 5, em que foi explorado o conceito de lados paralelos e não paralelos, obtivemos uma porcentagem de $78,6 \%$ de acertos em contraposição a $12,5 \%$ obtidos na diagnose inicial. Reafirma-se que o trabalho desenvolvido com o geoplano e com o GeoGebra mostrou-se determinante para a obtenção desse resultado. As análises a priori e a posteriori das situações de ensino, por meio da Engenharia Didática ou por outras formas, são importantes para auxiliar o professor, tanto para identificar as dificuldades dos alunos e dispor de meios de tratá-las como para avaliar os resultados de suas aulas e, consequentemente, tentar sempre melhorá-las.

Desse modo, ressaltamos a importância das situações adidáticas, como meios de construir engenharias didáticas centradas na TSD, nas quais os alunos têm o papel central na construção de seu próprio conhecimento. Reiteramos a importância da análise a priori e a posteriori, elementos da engenharia didática clássica que podem auxiliar os professores a planejar, executar, controlar e avaliar os resultados de suas aulas, mesmo quando estas não são desenvolvidas nos moldes desse trabalho.

\section{Conclusão}

O recorte de pesquisa apresentado nesse artigo teve como objetivo mostrar que mesmo apresentando dificuldades de desenvolver uma Engenharia Didática sobre o conceito de quadriláteros, tratando mais especificamente as noções de paralelismo e perpendicularismo, o estudo proposto permitiu mostrar a importância do aluno refletir sobre os conceitos e noções matemáticas desenvolvidos na escola, o que possibilitou ainda observar que as ideias e concepções do cotidiano apresentadas pelos alunos podem ser inseridas no contexto desse estudo, auxiliando a compreensão e motivação do conceito matemático estudado.

Durante a aplicação do quinto momento da sequência didática verificamos também que o uso de materiais manipuláveis, como o geoplano, a malha quadriculada e a pontilhada, contribuíram em grande parte para a construção dos conceitos geométricos acerca de quadriláteros e, mais particularmente, das noções de paralelismo e perpendicularismo. Ao compararmos os resultados da avaliação diagnóstica inicial com a final, aplicada após o desenvolvimento de todas as atividades dos diferentes momentos da sequência didática, constatamos que houve avanços consideráveis ao comparar quantitativamente, o número de respostas adequadas e não adequadas às questões que compuseram a diagnose em suas duas etapas de aplicação.

Considerando, mais especificamente o geoplano, foi possível verificar que os alunos utilizaram esse material de forma satisfatória e que ele se integrou ao meio, uma vez que alunos solicitaram, durante algumas atividades, o auxílio dessa ferramenta. No entanto, constatamos que alguns alunos ainda precisam controlar seus resultados por meio do material concreto, o que é também compreensível, dada a etapa escolar em que se encontram. Apesar da importância do geoplano como material manipulável, observamos que precisamos estar atentos à passagem do concreto para o abstrato.

Dessa forma, o geoplano representa uma das possibilidades de trabalho para a construção dos conhecimentos geométricos, sobretudo por se tratar de um material de fácil acesso, baixo custo e cuja utilização permite a manipulação e a visualização como elementos importantes na apropriação dos conteúdos propostos.

No que diz respeito à possibilidade de se propor estratégias de ensino do conteúdo de polígonos, admitimos que o trabalho com materiais manipuláveis, bem como a organização de grupos e o estímulo à socialização dos saberes construídos, 
são práticas efetivas que contribuem para a compreensão dos conteúdos geométricos.

Uma das experiências que merecem ênfase em um dos momentos da nossa sequência didática foi a construção de um instrumento de medida de ângulos cuja aplicação imprimiu maior significado a tal conceito e suas aplicações.

Percebemos que, em relação aos materiais manipuláveis, está em evidência o gosto pela descoberta, pela experimentação e pela construção e reconstrução de conceitos. Nesses moldes, acreditamos que sua utilização no processo de ensino e aprendizagem da Matemática e, mais particularmente da Geometria, de maneira mais específica, pode contribuir de fato para a construção de experiências lúdicas, dinâmicas e enriquecedoras.

Em nossa experiência com os alunos do quinto ano, foi possível atingir a validação interna de que trata a autora, tendo em vista o confronto que realizamos entre as análises a priori e a posteriori. Em muitos momentos, retomamos o quadro teórico que sustenta nossa pesquisa e revimos nossas próprias concepções diante de situações não previstas. Nesse ponto, reforçamos a importância de se construir situações adidáticas a partir da condução das diferentes instâncias do processo de ensino e aprendizagem. As diferentes questões que compuseram a avaliação diagnóstica permitiram realizar a análise prévia dos conceitos geométricos que os alunos já possuíam, possibilitando a retomada dos conteúdos ainda não assimilados durante a elaboração da sequência didática. Isso tornou possível a compreensão da realidade na qual pretendíamos intervir.

Ao sustentar nossa prática e a posterior análise dos resultados da aplicação da sequência didática aos postulados da Teoria das Situações Didáticas de Brousseau, foi possível evidenciar as condições sobre as quais os alunos produziram, comunicaram e aprenderam conteúdos a partir de situações em que puderam construir conhecimentos, formular estratégias de ação, validar as ações e os saberes. Embora tenha surgido a necessidade de intervenção da professora/ pesquisadora em muitos momentos da prática que deu origem a este artigo, observamos o progresso dos alunos em construir, de forma autônoma, seus conhecimentos sobre paralelismo e perpendicularismo. Este fato, por si só, já valida a proposição de novas intervenções nos moldes aqui descritos.

Em nosso trabalho, acreditamos que a Engenharia Didática tenha sido um importante referencial metodológico no processo de ensino e aprendizagem dos polígonos para os anos iniciais do Ensino Fundamental, uma vez que, ao comparar as análises a priori e a posteriori, podemos validar nossas hipóteses e compreender melhor as dificuldades dos alunos. Na proposição de novas tarefas, essa compreensão será traduzida em melhores meios de superação.

A proposta de atividade experimentada conservou e deu ênfase aos conceitos geométricos, no caso, relacionados aos conteúdos de polígonos e simetria, de forma ajustada às especificidades do meio escolar. Para realizar esta tarefa, houve a necessidade de inserir novos elementos ao meio (materiais e softwares). O planejamento e (re)construção do contexto, ancorados nas teorias apontadas neste trabalho, foram determinantes para o sucesso na execução da proposta.

$\mathrm{O}$ uso de metodologias adequadas exige tempo do professor, para preparar e organizar o material necessário, e a mudança no comportamento dos alunos e do professor, sendo que os primeiros passam de meros expectadores para atores do processo de ensino e aprendizagem enquanto que os segundos precisam estar cientes que seu papel é de mediador, devendo se manifestar somente quando houver bloqueio no desenvolvimento da situação. Observamos, então, uma alteração importante no contrato didático, uma vez que os alunos realizam as ações e a professora assume a função de mediadora da situação.

No entanto, é preciso deixar claro que mesmo aparentando relativa simplicidade, as atividades propostas foram pensadas em função do conteúdo geométrico sem perder de vista as especificidades do grupo de alunos que participaram da pesquisa. Sugere-se, para futuras experiências com o uso do GeoGebra, que sejam associadas outras atividades com malha quadriculada e pontilhada, além do geoplano.

Consideramos que as atividades realizadas pelos alunos nos indicam que esses, ao tentar encontrar uma maneira de solucionar as tarefas (no caso, as situações propostas), sentiram-se desafiados e, consequentemente, motivados durante a atividade. A partir da elaboração, aplicação e análise dessa sequência didática, acredita-se que outras possibilidades de trabalho podem surgir no campo da Educação Matemática, considerando as especificidades de cada turma e/ou assunto tratado.

\section{Referências}

Brousseau, G. (2011). Introdução ao estudo da teoria das situações didáticas: conteúdo e métodos de ensino. Tradução de: Camila Borges. São Paulo; Ática.

Brousseau, G. (2008). Introdução ao estudo das situações didáticas. São Paulo: Ática.

Brousseau, G. (1998). Théories des situations didactiques. Grenoble: La pensée Sauvage.

Brousseau, G. (1996). Os diferentes papéis do professor. In: C. Parra, I. Saiz. Didática da Matemática: reflexões psicopedagógicas. Porto Alegre: Artes Médicas.

Lorenzato, S. (Org.). (2015). Aprender e Ensinar Geometria. Campinas: Mercado das Letras.

Lorenzato, S. (2010). Laboratório de ensino de matemática e materiais didáticos manipuláveis. In: S. Lorenzato. (Org.). O Laboratório de ensino de matemática na formação de professores. Campinas: Autores Associados.

Lorenzato, S. (1995). Por que não ensinar Geometria? Rev. Soc. Bras. Educ. Matem, (4), p. 3-13

Nagata, R.S. (2016). Os níveis de desenvolvimento do pensamento geométrico: o aprendizado do conteúdo de polígonos numa perspectiva do modelo Van Hiele. Dissertação (Mestrado Profissional em Matemática- PROFMAT) - Universidade Tecnológica Federal do Paraná, UTFPR. Curitiba, PR, 120 f. 
Passos, C.L.B. (2010). Materiais manipuláveis como recursos didáticos na formação de professores de matemática. In: S. Lorenzato. Laboratório de Ensino de Matemática na formação de professores (pp.77-92). Campinas: Autores Associados.

Passos, C.L.B. (2000). Representações, interpretações e prática pedagógica: a Geometria na sala de aula. Tese (Doutorado em Educação) - Universidade Estadual de Campinas, Campinas, SP, 348p.

Pavanello, R.M. (1993). O abandono do ensino de Geometria no Brasil: causas e consequências. Zetetiké, (1),1, p. 1-17.

Proença, M.C., \& Pirola, N.A. (2009). A Formação de conceitos no ensino de matemática e física: um estudo exploratório sobre a formação conceitual em geometria de alunos do ensino médio. In: A. Caldeira. Ensino de ciências e matemática, II: temas sobre a formação de conceitos. São Paulo: UNESP.

Sampaio, H.R. (2008). Uma abordagem histórico-filosófica na educação matemática: contribuições ao processo de aprendizagem de trigonometria no ensino médio. Dissertação (Mestrado em Ensino de Ciências e Educação Matemática) - Universidade Estadual de Londrina, Londrina, PR, 192 f.

Zabala, A. (1998). A prática educativa: como ensinar. Porto Alegre: Artes Médicas. 